\title{
Neuroticism and Individual Differences in Neural Function in Unmedicated Major Depression: Findings From the EMBARC Study
}

\author{
Jay C. Fournier, Henry W. Chase, Tsafrir Greenberg, Amit Etkin, Jorge R. Almeida, \\ Richelle Stiffler, Thilo Deckersbach, Sarah Weyandt, Crystal Cooper, Marisa Toups, \\ Tom Carmody, Benji Kurian, Scott Peltier, Phillip Adams, Melvin G. Mclnnis, \\ Maria A. Oquendo, Patrick J. McGrath, Maurizio Fava, Myrna Weissman, Ramin Parsey, \\ Madhukar H. Trivedi, and Mary L. Phillips
}

\begin{abstract}
BACKGROUND: Personality dysfunction represents one of the only predictors of differential response between active treatments for depression to have replicated. We examine whether depressed patients with higher neuroticism scores, a marker of personality dysfunction, show differences compared with depressed patients with lower scores in the functioning of two brain regions associated with treatment response, the anterior cingulate and anterior insula cortices.

METHODS: Functional magnetic resonance imaging data during an emotional Stroop task were collected from 135 adults with major depressive disorder at four academic medical centers participating in the EMBARC (Establishing Moderators and Biosignatures of Antidepressant Response for Clinical Care) study. Secondary analyses were conducted including a sample of 28 healthy subjects.

RESULTS: In whole-brain analyses, higher neuroticism among adults with depression was associated with increased activity in and connectivity with the right anterior insula cortex to incongruent compared with congruent emotional stimuli (all $\mathrm{k} \geq 281$, all $p<.05$ familywise error corrected), covarying for concurrent psychiatric distress. We also observed an unanticipated relationship between neuroticism and reduced activity in the precuneus ( $k=269$, $p<.05$ familywise error corrected). Exploratory analyses including healthy subjects suggested that associations between neuroticism and brain function may be nonlinear over the full range of neuroticism scores.

CONCLUSIONS: This study provides convergent evidence for the importance of the right anterior insula cortex as a brain-based marker of clinically meaningful individual differences in neuroticism among adults with depression. This is a critical next step in linking personality dysfunction, a replicated clinical predictor of differential antidepressant treatment response, with differences in underlying brain function.
\end{abstract}

Keywords: Emotion regulation, fMRI, Major depressive disorder, Neuroticism, Precuneus, Right anterior insula http://dx.doi.org/10.1016/j.bpsc.2016.11.008

Neuroticism reflects the tendency to experience negative emotions and to cope poorly with affective states (1). High levels of neuroticism have enormous public health consequences, including impairments in work functioning (2), increased medical treatment utilization (2), and reduced longevity (3). Neuroticism is a strong vulnerability marker for the development of depression (4-9), but, critically, the clinical effects of neuroticism do not stop once an episode of depression emerges. To the contrary, markers of dysfunctional personality, including high levels of neuroticism, represent one of the only replicated prescriptive indicators of differential response between active treatments for depression (10-12). That is, among individuals with depression, individual differences in neuroticism and personality functioning exist, and these differences have consequences for the likelihood that a given treatment will be effective. Specifically, higher levels of neuroticism (12) and frank comorbid personality disorder (11) have each been associated with superior response to selective serotonin reuptake inhibitors compared with cognitive therapy, two generally effective treatments for depression (13). These patterns are reinforced by evidence that selective serotonin reuptake inhibitors may have strong specific effects, compared with placebo, in reducing levels of neuroticism itself, over and above changes in symptoms $(14,15)$. Although personality dysfunction does not invariably predict differential response across all forms of treatment [see $(16,17)]$, no other patient characteristic in the depression treatment outcome literature has so often been related to differential response 
across active treatments. However, the neural mechanisms driving these effects are unknown.

Neuroticism was initially conceptualized as a genetically based, biologically driven trait associated with heightened reactivity in limbic systems to stressors in the environment $(18,19)$. More recent work has revealed associations between neuroticism and the functioning of the subgenual anterior cingulate cortex (sgACC) and right anterior insula ( $\mathrm{rAl}$ ), regions implicated in the processing and regulation of emotionally relevant information (20-23). Haas et al. (24), for example, observed increased activity in the sgACC in healthy adults as a function of neuroticism during an emotional Stroop task. There are several reasons why individuals with higher levels of neuroticism may perform differently on such a task. The incongruent condition of an emotional Stroop task requires participants to manage competing, emotionally salient elements of the stimulus, control attentional resources in the presence of a distractor, and select the appropriate response while suppressing a competing response. Even with nonemotional stimuli, neuroticism is associated with general difficulties in the control of attentional resources, which manifests in tasks involving attention capture, selective attention, and disengagement of attention from distracting information (25-27). These effects may be further exacerbated when stimuli are negative (27) or emotionally relevant, given the salience of such information $(28,29)$. Furthermore, there is mounting evidence suggesting that neuroticism may also be associated with individual differences in neural activity in a key part of the salience network. Together with more dorsal portions of the ACC, the rAl is believed to be a critical region involved in salience detection $(22,23)$. Increased activity in the rAl has been associated with neuroticism in healthy samples across a wide variety of emotionally relevant tasks for which salience detection is a key feature, including loss anticipation (30), emotion processing (31), pain perception (32), and decision making $(33,34)$.

Converging evidence from treatment trials examining patterns of brain activity associated with response to treatments for depression suggests key roles for individual differences in the functioning of the SgACC and $\mathrm{rAl}$ in predicting differential treatment outcomes. Specifically, several observational treatment studies suggest that higher activity in the sgACC (both at rest and during tasks) is associated with better response to antidepressant medications [see (35)], whereas lower sustained activity during emotion processing is associated with better response to cognitive therapy $(36,37)$. By contrast, the sole randomized controlled trial examining neural predictors of treatment outcome did not observe that the sgACC differentiated response to antidepressant and cognitive therapy treatments. Rather, the $\mathrm{rAl}$ was the region that most clearly predicted differential response: subjects with higher metabolism in this region at rest were more likely to remit with drug treatment and less likely to remit with cognitive therapy, and vice versa (38).

In this study, we used functional magnetic resonance imaging (fMRI) to examine whether depressed individuals with high levels of neuroticism (vs. depressed individuals with lower levels of neuroticism) displayed increased activity in the sgACC and rAl during a variant of the face-word emotional Stroop task. Activity in both brain regions has been associated with neuroticism and separately with differential treatment response in depression. Tasks such as the emotional Stroop task that require cognitive and attentional control in the context of emotional processing reliably elicit activity in anterior insula and sgACC regions (39). Thus, the emotional Stroop task provides a promising probe of the role of neuroticism in brain function in depression. This study is a first step to determine whether activity in these two brain regions might represent core neural markers of clinically meaningful individual differences in depression that may help to explain the association between personality dysfunction and differential treatment response. In secondary analyses, we incorporate data from a small sample of healthy control $(\mathrm{HC})$ subjects to examine associations with neuroticism across the full range of neuroticism scores.

\section{METHODS AND MATERIALS}

\section{Participants}

Study participants were recruited as part of the EMBARC (Establishing Moderators and Biosignatures of Antidepressant Response for Clinical Care) study, a multisite randomized controlled trial examining medication treatment of depression $(40,41)$. All data came from baseline assessments before treatment. The initial sample comprised 190 individuals with a current diagnosis of major depressive disorder (MDD) who were not currently receiving treatment and who completed the fMRI task at one of the four scanning sites: Columbia University, Massachusetts General Hospital, the University of Michigan, and the University of Texas Southwestern Medical Center. In secondary analyses, data from $40 \mathrm{HC}$ subjects were incorporated to determine the effects of neuroticism across the full range of scores. Psychiatric diagnoses were made using the Structured Clinical Interview for DSM-IV Axis I Disorders (42). Full inclusion and exclusion criteria have been reported elsewhere (41) and are described in the Supplement. The study was approved by the institutional review boards at each site. All participants provided written informed consent.

Of the original sample, data from 49 MDD subjects and $9 \mathrm{HC}$ subjects were excluded owing to excessive motion $(>4 \mathrm{~mm})$, low signal-to-noise ratio $(<80)$, technical issues, or artifacts in fMRI data. Three additional MDD subjects were excluded owing to poor behavioral performance (accuracy $<70 \%$ ), and three participants from each group were excluded owing to missing data on core clinical measures. This yielded a final sample of $135 \mathrm{MDD}$ subjects and $28 \mathrm{HC}$ subjects, representing data loss of $28.9 \%$ and $30.0 \%$, respectively, $\chi^{2}{ }_{1}=0.02, p=.89$, consistent with other neuroimaging data sets (38).

\section{Clinical Measures}

Neuroticism was assessed using the NEO Five-Factor Inventory-3 (43). Because neuroticism scores can be highly correlated with symptom measures (44), we covaried for psychiatric symptoms (see below). Depressive symptoms were assessed using the 24-item Hamilton Depression Rating Scale (45). Subscales of the Mood and Anxiety Symptom Questionnaire were used to assess anhedonia and anxious arousal $(46,47)$. 


\section{Paradigm}

The Emotional Conflict Task (48) was used as an emotional Stroop task to probe implicit emotion reactivity and regulation processes during the presentation of conflicting emotional information. Stimuli consisted of 148 pictures of emotional faces (happy or fearful), and participants were asked to label the expression while ignoring an emotion word ("happy" or "fear") that overlaid the image. The emotion words either matched the emotional faces (congruent trials) or conflicted with them (incongruent trials). Stimuli were presented for 1000 $\mathrm{ms}$, with a variable interstimulus interval (3000-5000 ms, mean $4000 \mathrm{~ms}$ ), in a pseudorandom order, counterbalanced as a function of expression, word, gender, and response button. Before the scan, participants practiced the task and were required to achieve $>85 \%$ accuracy.

\section{Neuroimaging Data Acquisition}

Structural and functional MRI data were collected at each site using 3T MRI scanners. See the Supplement for detailed acquisition parameters.

\section{Functional Neuroimaging Data Preprocessing}

Preprocessing of functional images was implemented using Nipype software (http://nipy.org/nipype), using a combination of modules from different software packages. The first five volumes of the run were discarded. Functional images were realigned using SPM8 (http://www.fil.ion.ucl.ac.uk/spm), coregistered to the participant's structural image, and normalized to Montreal Neurological Institute space using a linear affine transformation implemented in FSL (http://fsl.fmrib.ox.ac.uk) fsl/fslwiki/). Montreal Neurological Institute space was defined using the OASIS template (http://www.oasis-brains.org), with a resolution of $2 \mathrm{~mm}$ isotropic. AFNI 3dDespike (http://afni.nimh. nih.gov/afni) was used to address spikes in signal intensity (using 3 SD and 5 SD cutoffs for spikes and deviations from the curve, respectively). Finally, data were spatially smoothed using an 8-mm adaptive kernel (FSL).

\section{Functional Neuroimaging Data Analyses}

First-level models were estimated using SPM8. Models were fit separately for each participant and included regressors for each trial type, along with nuisance regressors representing the first trial of the block, error trials, and posterror trials. Regressors were convolved with the canonical hemodynamic response function. Temporal derivatives of the hemodynamic response function and the six movement parameters were included as variables of no interest. A high-pass filter $(60$ seconds) was used. For the current study, the contrast between incongruent and congruent trials served as the comparison of interest (additional details in the Supplement).

Whole-brain voxelwise analyses were conducted at the second level to examine between-persons effects. Consistent with prior EMBARC reports, all models covaried for scanning site, gender, and age. The primary aim of the study was to examine differences between MDD as a function of neuroticism. As such, the best control participants for examining neural function of individuals with MDD and high levels of neuroticism are individuals with MDD and lower levels of neuroticism. Thus, the primary whole-brain analyses focused exclusively on the effects of neuroticism in MDD. Because measures of neuroticism can be contaminated with current distress, we additionally covaried for current levels of depression, anhedonia, and anxiety. Secondary whole-brain analyses incorporated data from the HC group. The lack of overlap in neuroticism scores between the groups (Supplemental Figure S2) precluded us from examining the group-by-neuroticism interaction effect to determine whether the effect of neuroticism differed between the groups. To ascertain whether the effect of neuroticism was similar at the lower $(\mathrm{HC})$ and higher (MDD) ends of the range, we included both linear and curvilinear (neuroticism ${ }^{2}$ ) terms in the model (additional details in the Supplement).

Voxelwise regression analyses were implemented using the GLM Flex suite of software tools (http://mrtools.mgh.harvard. edu/index.php/Main_Page). This software uses all available data to estimate the model in a given voxel. See Supplemental Figure S1 for a map of sample sizes per voxel (minimum $n=32$ ). Statistical inferences were made on the basis of cluster level statistics (cluster forming threshold $p<.005$, uncorrected, extent threshold $p<.05$ familywise error [FWE] corrected). Given that the size of the effect of neuroticism on neural function in depression is currently unknown, these thresholds were chosen a priori as a way of balancing protection from both type I and II errors (49).

To explore whether neuroticism was also associated with differences in connectivity between brain regions, we conducted exploratory generalized psychophysiological interaction analyses (50). Given the findings reported below, we used as the seed region a mask of the dorsal rAl derived from a relevant parcellation study of the insula (51). First-level and second-level models were the same as those described above.

\section{Clinical, Demographic, and Behavioral Data Analyses}

Associations with clinical, demographic, and behavioral data were examined with SAS version 9.4 (SAS Institute Inc., Cary, $\mathrm{NC})$. Associations with neuroimaging data were examined using parameter estimates extracted from significant clusters of activity. Reaction time data were log-transformed when examined as the dependent variable. Differences in accuracy were examined using Poisson regression models of error rates, with robust standard errors where appropriate (52).

\section{RESULTS}

\section{Primary Analyses: Neuroticism in MDD}

Clinical Features and Behavioral Results. Table 1 displays demographic and clinical characteristics. The distribution of neuroticism scores in the MDD group (Supplemental Figure S2) was centered (mean $=68.85, \mathrm{SD}=7.86$ ) nearly $2 \mathrm{SD}$ higher than published population norms (mean $=50$, $\mathrm{SD}=10$ ) (43), consistent with the level and variability of neuroticism scores observed in previous samples of patients with depression (53). Depression severity was the only variable significantly associated with neuroticism in the MDD group. As expected, Wilcoxon signed rank tests of within-subject effects revealed that accuracy for the incongruent condition was lower than accuracy for the congruent condition $(p<.001)$, 
Table 1. Demographic and Clinical Characteristics

\begin{tabular}{|c|c|c|c|c|c|}
\hline \multirow[b]{2}{*}{ Variable } & \multirow[b]{2}{*}{ MDD Group $(n=135)$} & \multirow[b]{2}{*}{ HC Group $(n=28)$} & \multirow[b]{2}{*}{ Effect of Group } & \multicolumn{2}{|c|}{ Association With Neuroticism } \\
\hline & & & & MDD Group & Full Sample \\
\hline \multicolumn{6}{|l|}{ Demographic } \\
\hline Female, \% & 67.41 & 60.71 & $\chi_{1}^{2}=0.46$ & $r_{\mathrm{pb}}=-.02$ & $r_{\mathrm{pb}}=.03$ \\
\hline Married, \% & $20.90^{a}$ & 17.86 & $\chi^{2}{ }_{1}=0.13$ & $r_{\mathrm{pb}}=-.17$ & $r_{\mathrm{pb}}=-.06$ \\
\hline Unemployed, $\%^{b}$ & 48.06 & 23.08 & $\chi_{2}^{2}=6.39^{c}$ & $\rho=.09$ & $\rho=.20^{c}$ \\
\hline Age, mean (SD) & $36.51(12.56)$ & $37.39(16.08)$ & $t_{161}=-0.32$ & $r=-.11$ & $r=-.10$ \\
\hline Years of education, mean (SD) ${ }^{d}$ & $14.84(2.46)$ & $15.82(5.04)$ & $t_{29.71}=-1.01$ & $r=.002$ & $r=-.09$ \\
\hline $\mathrm{IQ}$, mean $(\mathrm{SD})^{e}$ & $114.85(12.07)$ & $118.42(13.07)$ & $t_{137}=-1.30$ & $r=.003$ & $r=-.08$ \\
\hline \multicolumn{6}{|l|}{ Behavioral Performance } \\
\hline Correct, incongruent $(\%)^{f}$ & $93.88(5.15 \%)$ & $93.49(5.17 \%)$ & $z=-0.37$ & $z=-0.08$ & $z=0.22$ \\
\hline Correct, congruent $(\%)^{f}$ & $96.91(3.86 \%)$ & $97.38(2.76 \%)$ & $z=0.74$ & $z=-0.15$ & $z=0.94$ \\
\hline Reaction time, incongruent, mean (SD) ${ }^{g}$ & $782.59(138.81)$ & $794.23(186.48)$ & $t_{161}=-0.16$ & $r=.07$ & $r=.03$ \\
\hline Reaction time, congruent, mean (SD) ${ }^{g}$ & $718.36(123.10)$ & $729.84(164.55)$ & $t_{161}=-0.23$ & $r=.05$ & $r=.02$ \\
\hline \multicolumn{6}{|l|}{ Clinical Measures } \\
\hline Neuroticism, mean (SD) & $68.85(7.86)$ & $36.39(7.24)$ & $t_{161}=20.15^{h}$ & - & - \\
\hline HDRS, mean (SD) ${ }^{d}$ & $26.61(5.50)$ & $0.71(1.01)$ & $t_{160.17}=50.74^{h}$ & $r=.18^{c}$ & $r=.79^{h}$ \\
\hline MASQ-Anhedonia, mean (SD) ${ }^{d}$ & $43.77(5.22)$ & $26.04(7.95)$ & $t_{31.98}=11.31^{h}$ & $r=.14$ & $r=.71^{h}$ \\
\hline MASQ-Anxiety, mean (SD) ${ }^{d}$ & $17.67(5.90)$ & $10.79(0.99)$ & $t_{158.49}=12.73^{h}$ & $r=.13$ & $r=.43^{h}$ \\
\hline \multicolumn{6}{|l|}{ Clinical Features } \\
\hline Duration of episode, months, mean (SD) & $36.75(60.90)$ & - & & $r=.01$ & \\
\hline Age of onset, years, mean (SD) & $16.13(5.90)$ & - & & $r=-.10$ & \\
\hline Recurrent, $\%{ }^{j}$ & 86.36 & - & & $r_{\mathrm{pb}}=-.04$ & \\
\hline Melancholic, \% & 38.52 & - & & $r_{\mathrm{pb}}=-.06$ & \\
\hline Atypical, \% & 30.37 & - & & $r_{\mathrm{pb}}=.06$ & \\
\hline Current anxiety disorder, \% & 37.04 & - & & $r_{\mathrm{pb}}=.01$ & \\
\hline Current eating disorder, \% & 1.48 & - & & $r_{\mathrm{pb}}=.17$ & \\
\hline Lifetime alcohol/substance disorder, \% & 22.22 & 7.14 & Fisher's exact: $p=.07$ & $r_{\mathrm{pb}}=.08$ & $r_{\mathrm{pb}}=.16^{C}$ \\
\hline
\end{tabular}

$\mathrm{HC}$, healthy control; HDRS, Hamilton Depression Rating Scale; MASQ, Mood and Anxiety Symptoms Questionnaire; MDD, major depressive disorder; $r_{\mathrm{pb}}$, point biserial correlation.

${ }^{a}$ Data were missing from 1 participant.

${ }^{b}$ Data were missing from 2 participants (MDD group) and considered not classifiable as employed vs. unemployed for 6 others (4 in the MDD group, 2 in the $\mathrm{HC}$ group).

${ }^{c} p<.05$.

${ }^{d}$ The Satterthwaite method was used owing to inequality of variances.

${ }^{e}$ Data were missing from $20 \mathrm{MDD}$ and $4 \mathrm{HC}$ participants.

${ }^{f}$ Owing to the shape of the distributions, data were examined using Poisson regression models of error rates using robust standard errors.

${ }^{g}$ Reaction time data were log-transformed for analyses.

${ }^{h} p<.001$.

${ }^{i}$ Data were missing from 2 participants.

${ }^{j}$ Data were missing from 3 participants.

and dependent $t$ tests revealed significantly slower reaction times to the incongruent compared with the congruent conditions $\left(t_{134}=20.25, p<.001\right)$. Neuroticism was not significantly associated with behavior (Table 1 ).

Task Effects. As expected, significantly greater blood oxygen level-dependent (BOLD) response to incongruent, compared with congruent, stimuli was observed for the MDD group in the anterior insula cortex, cingulate, dorsolateral prefrontal cortex (PFC), lateral parietal cortex, precuneus, and thalamus, along with activity in motor regions, fusiform gyrus, cerebellum, and right middle temporal gyrus (Figure 1 and Table 2). We also observed a significant negative effect (which represented greater negative relative BOLD signal during the incongruent compared with the congruent condition) (Table 2) in the frontal pole.

Effect of Neuroticism on BOLD Response. We observed a significant positive relationship in whole-brain analyses between neuroticism and activity in the dorsal rAl in MDD $(\mathrm{k}=281$, FWE corrected $p=.03$; peak, $t=3.76 \mathrm{x}=32, \mathrm{y}=22$, $z=-2$ ) (Figure 2A) to the incongruent compared with the congruent conditions, covarying for current depression, anhedonia, and anxiety symptoms. We also observed a significant negative relationship in the left precuneus $(k=269$, FWE corrected $p=.04$; peak, $t=-4.27 \mathrm{x}=0, \mathrm{y}=-64, \mathrm{z}=30$ ) (Figure 2B), owing to a weaker positive relationship between neuroticism and BOLD response to the incongruent compared 


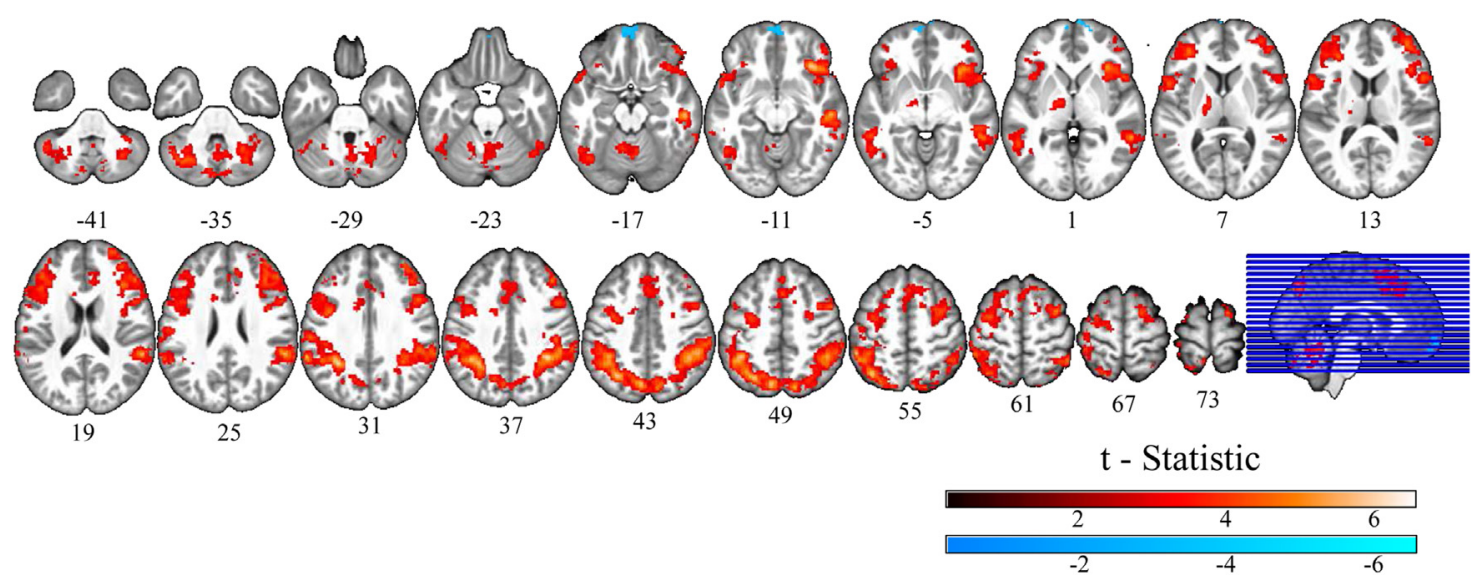

Figure 1. Neural correlates of the incongruence effect in major depressive disorder. Significant clusters $(p<.05$ familywise error corrected) of blood oxygen level-dependent response to the incongruent-minus-congruent contrast across the depressed group.

with the congruent conditions in this region (Figure 2B, inset). Secondary analyses of extracted data revealed that the effect of neuroticism remained significant in both the rAl and the precuneus regions (all $F \geq 5.51$, all $p \leq .03$ ) when covarying for demographic and clinical variables (see the Supplement for additional details). Furthermore, we repeated the primary wholebrain models examining neuroticism on its own [see $(54,55)]$ and observed two similar clusters: a significant cluster in the dorsal rAl that extended in the frontal operculum $(k=419$, FWE corrected $p=.004)$ and a cluster that was just shy of significance in the left precuneus $(\mathrm{k}=233$, FWE corrected $p=.09)$.

Effect of Neuroticism on Functional Connectivity. Given the findings in the dorsal rAl noted above and given this region's association with other large-scale cortical networks, we used a dorsal rAl mask from a recent parcellation study of the insula as the seed region for whole-brain generalized psychophysiological interaction analyses (51), and we overlaid significant results on a map generated by a recent parcellation of large-scale cortical networks (56). We observed three significant clusters (Figure 3 ) demonstrating reduced connectivity with the dorsal $\mathrm{rAl}$ as a function of neuroticism to incongruent versus congruent stimuli: a cluster in the lateral PFC (lateral Brodmann area 10) localized in a region associated with the frontoparietal control network $(\mathrm{k}=287$, FWE corrected $p=.03$; peak, $t=-4.08 \mathrm{x}=42, \mathrm{y}=50, \mathrm{z}=-2$ ); a cluster in a thin strip of cortex in the inferior middle and posterior cingulate, also associated with the frontoparietal control network $(\mathrm{k}=$ 448, FWE corrected $p=.002$; peak, $t=-5.01 \mathrm{x}=4, \mathrm{y}=-12$, $z=26)$; and a cluster in the occipital lobe, associated with the visual network and extending ventrally into the cerebellum $(\mathrm{k}=1048$, FWE corrected $p<.001$; peak, $t=-4.45$ $x=-6, y=-78, z=-8$ ). In each cluster, the negative association was due to reduced connectivity during incongruent and increased connectivity during congruent stimuli (Figure 3, inset). As above, the effect of neuroticism in each cluster remained significant when demographic and clinical variables were covaried (all $F \geq 13.80$, all $p \leq .001$ ) (details in the Supplement along with an analysis of the effects of scanner site).

Table 2. Coordinates of Clusters Showing Significant Task Effects Among Patients With MDD (Incongruent-Congruent)

\begin{tabular}{|c|c|c|c|c|c|c|c|c|c|}
\hline \multirow[b]{2}{*}{$\mathrm{k}$} & \multirow[b]{2}{*}{ FWE Corrected $p$} & \multirow[b]{2}{*}{ Hemisphere } & \multirow[b]{2}{*}{ Region } & \multirow[b]{2}{*}{$t$} & \multirow[b]{2}{*}{$\mathrm{x}$} & \multirow[b]{2}{*}{$\mathrm{y}$} & \multirow[b]{2}{*}{ z } & \multicolumn{2}{|c|}{ Stimulus Effects, Mean (SD) ${ }^{a}$} \\
\hline & & & & & & & & Incongruent & Congruent \\
\hline \multicolumn{10}{|c|}{ Positive Effect } \\
\hline \multirow[t]{3}{*}{20,638} & $<.001$ & $\mathrm{R} / \mathrm{L}$ & Parietal (IPL, SMG, SPL, ANG, precuneus) & 6.12 & 40 & -46 & 38 & $0.58(1.16)$ & $0.23(1.14)$ \\
\hline & & $\mathrm{R} / \mathrm{L}$ & $\begin{array}{l}\text { Frontal (IFG, MFG, SFG, precentral gyrus, } \\
\text { postcentral gyrus, operculum) }\end{array}$ & & & & & & \\
\hline & & $\mathrm{R}$ & Temporal (MTG, STG) & & & & & & \\
\hline 2315 & $<.001$ & $\mathrm{R} / \mathrm{L}$ & Cerebellum & 4.61 & -14 & -54 & -20 & $2.21(1.76)$ & $1.86(1.72)$ \\
\hline 1129 & $<.001$ & $\mathrm{~L}$ & Fusiform/MTG & 5.43 & -42 & -66 & -20 & $1.22(1.42)$ & $0.94(1.37)$ \\
\hline 270 & .04 & $\mathrm{~L}$ & Thalamus & 3.91 & -14 & -12 & 6 & $0.61(1.08)$ & $0.38(1.03)$ \\
\hline \multicolumn{10}{|c|}{ Negative Effect } \\
\hline 267 & .04 & - & Frontal pole & -3.88 & 8 & 70 & 2 & $-0.99(2.23)$ & $-0.57(2.08)$ \\
\hline
\end{tabular}

The main effects of scanning site, gender, and age were covaried. Cluster forming threshold $p<.005$ uncorrected, cluster extent threshold $p<.05$ FWE corrected.

ANG, angular gyrus; FWE, familywise error; IFG, inferior frontal gyrus; IPL, inferior parietal lobule; L, left; MDD, major depressive disorder; MFG, middle frontal gyrus; MTG, middle temporal gyrus; R, right; SFG, superior frontal gyrus; SMG, supramarginal gyrus; SPL, superior parietal lobule; STG, superior temporal gyrus.

${ }^{a} \beta$ values for each stimulus type were extracted from the clusters and averaged over the MDD sample. 


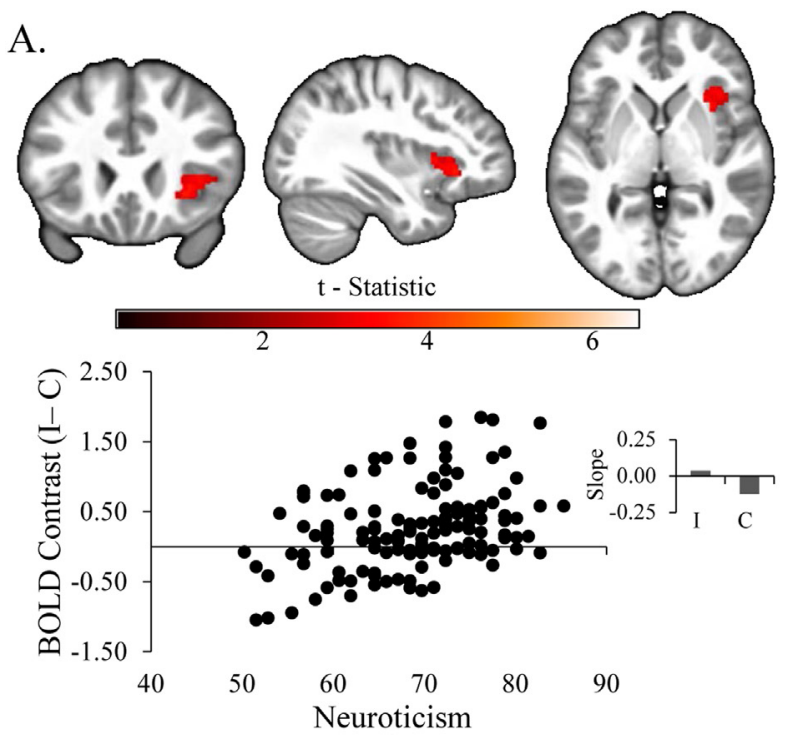

B.
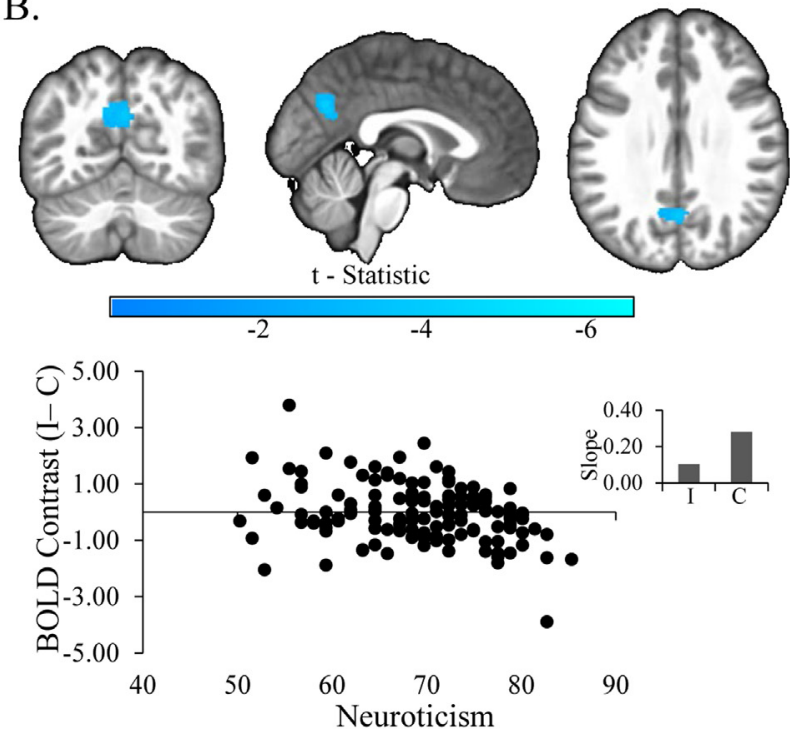

Figure 2. Effect of neuroticism on blood oxygen level-dependent (BOLD) response in major depressive disorder. Significant clusters of positive (A) and negative (B) relationships between neuroticism and brain activity among adults with major depressive disorder, covarying for the effects of site, gender, age, depression, anhedonia, and anxiety. Scatterplots are provided for display purposes only. They depict the bivariate relationships between neuroticism (abscissa) and BOLD response in the significant clusters (ordinate), represented by the $\beta$ coefficient associated with the incongruent-minus-congruent $(\mathrm{I}-\mathrm{C})$ contrast. Insets display slope estimates (standardized $\beta$ s from regression models of extracted data, covarying for the above variables) representing the relationship between neuroticism and BOLD response to each stimulus type.

\section{Secondary Analyses: Neuroticism in the Combined MDD and HC Samples}

As displayed in Table 1, the HC and MDD groups were well matched on demographic variables with the exception of employment rates. Neuroticism levels among $\mathrm{HC}$ subjects (mean $=36.39, \mathrm{SD}=7.24)$ were substantially $(\approx 1.5 \mathrm{SD})$ lower than population norms, likely owing to strict inclusion criteria. In line with prior reports [e.g., $(57,58)]$, when the full range of clinical scores was considered across the full sample, neuroticism was significantly associated with depression, anhedonia, and anxiety symptoms as well as employment status and past alcohol and substance abuse diagnoses (Table 1).

We used repeated measures linear and Poisson regression models to examine the effects of group, condition, and groupby-condition interaction on reaction times and error rates, respectively. Incongruent stimuli were associated with longer reaction times $\left(F_{1,161}=267.90, p<.001\right)$ and higher error rates $\left(F_{1,161}=25.40, p<.001\right)$ than congruent stimuli. Neither the main effect of group nor the group-by-condition interaction was significant in either analysis (all $F<0.53$, all $p>.46$ ). Neuroticism was not associated with behavior in any condition, in either group (Table 1).

\section{Effect of Neuroticism on BOLD Response Across the} Sample. In whole-brain analyses across the full sample, we did not observe a significant effect of group or a linear effect of neuroticism on BOLD response (all $\mathrm{k}<190$, FWE corrected $p>$.05). Rather, we observed a significant curvilinear relationship between neuroticism and BOLD response to the incongruent compared with the congruent conditions in a cluster including the rAl and extending into the frontal operculum and laterally to Brodmann area $45(k=293$, FWE corrected $p=.03$; peak, $t=3.85 \mathrm{x}=28, \mathrm{y}=20, \mathrm{z}=4$ ) (Supplemental Figure S3), whereby subjects with lower and higher levels of neuroticism had the highest BOLD response in this region.

\section{Effect of Neuroticism on Connectivity Across the}

Sample. Using the same dorsal rAl seed described above, we observed a significant effect of group on connectivity between the seed and a cluster in portions of the left superior parietal lobule and precuneus associated with the dorsal attention network, with anterior extension into white matter $(\mathrm{k}=695$, FWE corrected $p<.001$; peak, $t=3.89 \mathrm{x}=-32$, $y=-20, z=30$ ) (Supplemental Figure S4). This effect was driven by reduced connectivity to the incongruent compared with the congruent conditions in the $\mathrm{HC}$ group compared with the MDD group. Finally, we observed a significant inverse curvilinear effect of neuroticism on connectivity during the incongruent compared with the congruent conditions between the dorsal rAl seed and a cluster in the lateral PFC localized in a region associated with the frontoparietal control network $(\mathrm{k}=278$, FWE corrected $p=.04$; peak, $t=-4.44 \mathrm{x}=38$, $y=50, z=18$ ) (Supplemental Figure S4), such that connectivity was highest for subjects in the middle range of the neuroticism scale.

\section{DISCUSSION}

Adults with depression differ from one another regarding personality features, and these differences have consequences for the likelihood of success of particular treatments $(11,12)$. In this study, we observed that individuals with depression with higher neuroticism had increased activity in the $\mathrm{rAl}$ and decreased activity in the left precuneus during an 


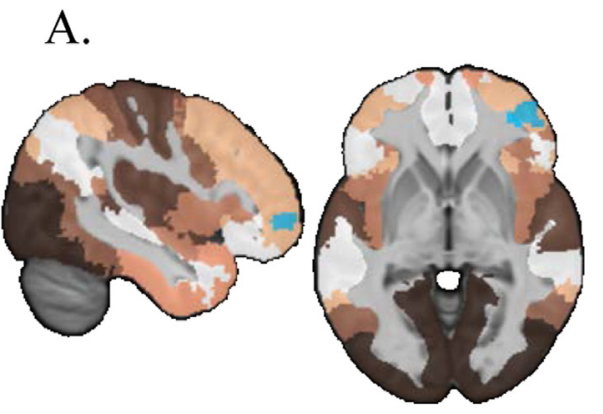

B.

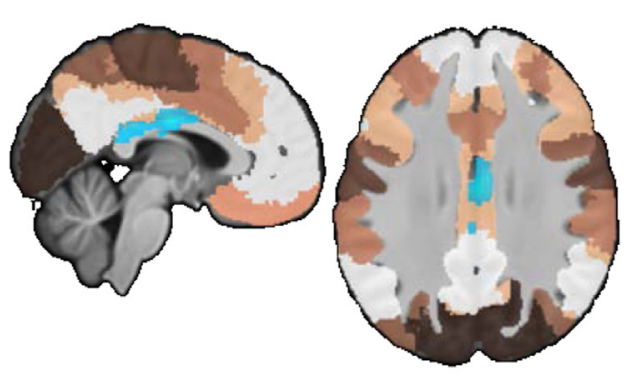

C.

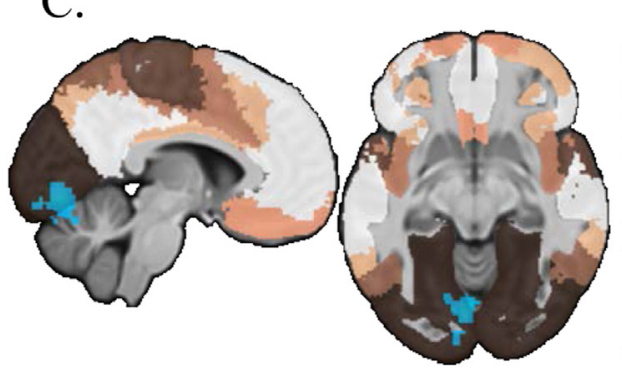

$\mathrm{t}$ - Statistic
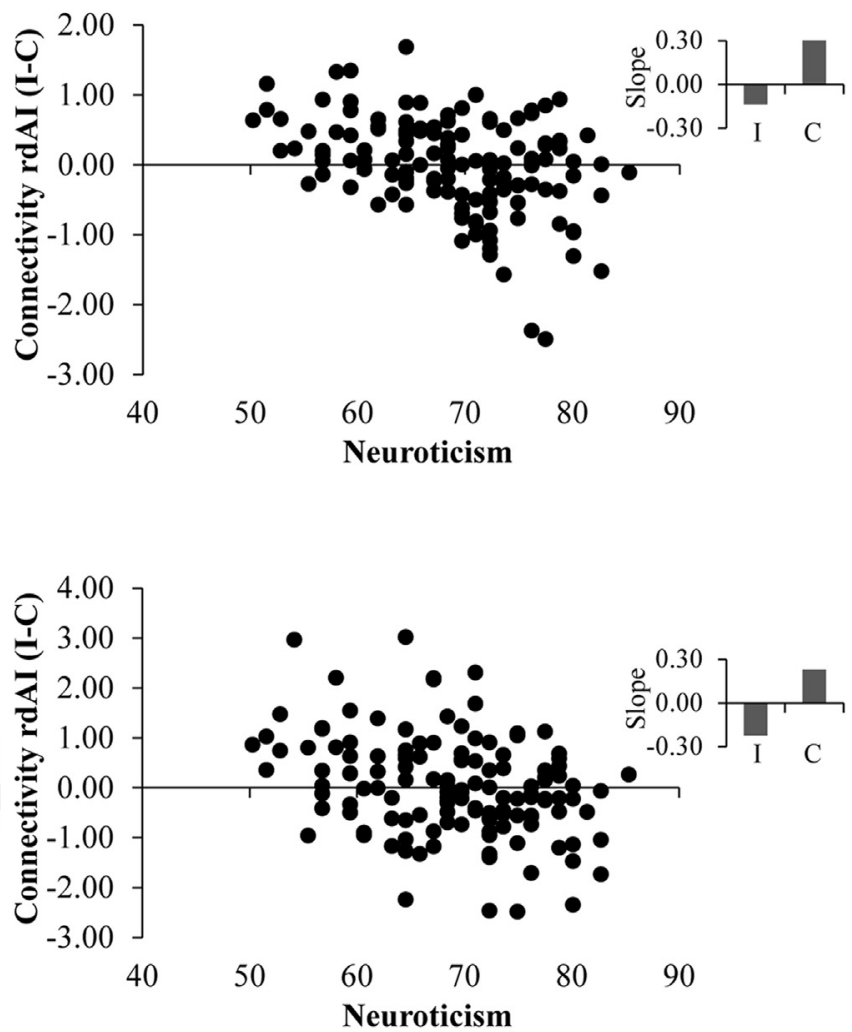

Neuroticism

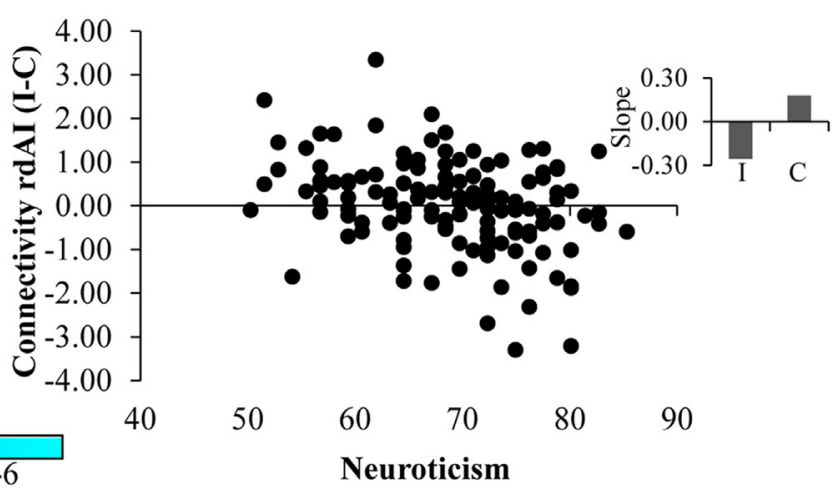

Visual

Somatomotor

Dorsal attention

Ventral attention

Figure 3. (A-C) Effect of neuroticism on functional connectivity with the right dorsal anterior insula (rdAl) in major depressive disorder. Significant clusters represent results of generalized psychophysiological interaction analyses using an rdAl seed derived from a recent parcellation study (51). To aid interpretation, clusters have been overlaid on the seven-network parcellation of large-scale cortical networks derived by Yeo et al. (56). Scatterplots are provided for display purposes only. They depict the bivariate relationships between neuroticism (abscissa) and parameter estimates (ordinate) of the contrast in connectivity during the incongruent (I) vs. congruent (C) conditions. Insets display slope estimates (standardized $\beta$ s from regression models of extracted data, covarying for the above variables) representing the relationship between neuroticism and connectivity parameter estimates for each stimulus type.

emotional Stroop task. The relationship between neuroticism and rAl activity was hypothesized, given findings linking neuroticism to activity in this region among $\mathrm{HC}$ subjects
(30-34,59), findings linking personality dysfunction to antidepressant treatment response (10-12), and findings linking antidepressant treatment response to activity in this region $(38,60)$. 
Thus, this study provides convergent evidence for the importance of activity in the rAl for understanding clinically meaningful individual differences among patients with MDD.

The anterior insula has been implicated in a wide variety of cognitive and emotional regulation processes and is believed to be a central component of the salience network $(22,23)$. One set of theories $(23,61)$ contends that the anterior insula, and particularly the dorsal anterior insula, is pivotal for adaptively switching between the default mode and central executive networks to appropriately process salient stimuli $(22,62)$. One possible interpretation of the present findings is that individuals high in neuroticism may display altered salience processing during the presentation of emotional information. Poorly tuned salience detection could result in faulty cortical network switching. This hypothesis is further supported by the results of exploratory functional connectivity analyses in which we observed reduced connectivity between the dorsal rAl and two regions (one in the lateral $\mathrm{PFC}$ and one in the midcingulate and/or posterior cingulate) associated with the frontoparietal cognitive control network.

We did not hypothesize the negative relationship between neuroticism and activity in the precuneus. The ventral precuneus, in which the findings were localized, has been included as a key node of the default mode network $(63,64)$. The negative observed relationship was due to increased activity to the congruent compared with incongruent condition, which could reflect deficits in the switch from default mode processing when responding to the congruent stimuli, the easier of the two conditions $(35,65,66)$. This hypothesis fits well with the possibility that neuroticism may be associated with abnormalities in large-scale cortical network switching; however, these hypotheses require testing in future work with tasks designed specifically to examine these processes.

We did not observe the hypothesized relationship between neuroticism and activity in the sgACC. This stands in contrast to two prior sets of findings. Haas et al. (24) observed an association between neuroticism and activity in this region among healthy individuals. Webb et al. (67), using scalp recorded electroencephalogram data collected at rest from the same parent study as the data reported herein, observed that increased resting electroencephalogram (gamma current density) signal localized to the sgACC was associated with increased neuroticism scores. In contrast to the study by Haas et al. (24), we collected data on relatively few individuals from the middle of the neuroticism range. It is possible that the relationship is strongest over this portion of the range and dissipates at the extremes. In secondary analyses of BOLD response, we observed strong evidence of nonlinear relationships between neuroticism and neural response. Comparison with the findings by Webb et al. (67) suggests that there may be a dissociation between task and rest states in the relationship between neuroticism and the functioning of the sgACC in patients with MDD. Future work will need to examine this possibility as well as whether activity in this region in response to different kinds of emotional tasks might be associated with neuroticism.

In secondary analyses, we did not observe mean differences in behavioral performance or BOLD response between the MDD and HC groups. However, we did observe reduced connectivity in the $\mathrm{HC}$ group relative to the MDD group between the dorsal rAl and regions associated with the dorsal attention network. Perhaps the most notable findings from the secondary analyses were the observations of curvilinear relationships between neuroticism and BOLD response in an rAl-frontal-opercular cluster and between neuroticism and measures of functional connectivity between the dorsal-rAl and lateral PFC. These findings suggest that the relationship between neuroticism and brain activity in and connectivity with the rAl may not be simple or linear. Notably, the present findings occur in the context of a broader literature that is mixed regarding the nature, location, and direction of MDD$\mathrm{HC}$ differences in neural function (68-71). We contend that this variability may stem, in part, from the complex relationships between diagnostic status, neuroticism, and brain activity. Whether differences between MDD and HC groups are observed may depend on which parts of the neuroticism spectrum have been sampled in each group.

Many studies, similar to this one, adopt an extreme groups sampling approach to assess the neural correlates of important participant characteristics. Although such approaches have notable strengths, one limitation is that it can be difficult to ascertain the nature of the relationship between the construct in question and brain activity over the middle of the range. It will be important for future work regarding broad dimensions of psychological functioning, conducted in accordance with the Research Domain Criteria initiative (72), to sample across the range of possible scores on dimensional measures and to consider nonlinear relationships with brain function. Additional limitations to the present study include the fact that the sample sizes from the MDD and HC groups were imbalanced, which could have affected power to detect between-group differences. Also, the shorter version of the NEO instruments was used to assess neuroticism. As such, it was not possible to calculate reliable subscales of neuroticism to examine which subscales were driving the observed effects.

\section{Conclusions}

The current findings are among the first to link a clinical characteristic (personality dysfunction) with neural markers (functioning of the rAl)-both of which have been associated with differential response to treatments for depression. This is an important next step for understanding the neural basis of clinically meaningful dimensions on which patients with depression differ, and it provides a target for future work to examine the mechanisms through which alterations in brain function affect treatment outcomes. Once these processes are better understood, it may be possible not only to better tailor existing treatments for specific individuals, but also to develop novel strategies that can more efficiently target an individual's underlying pathology.

\section{ACKNOWLEDGMENTS AND DISCLOSURES}

This work was supported by the National Institutes of Health (NIH) National Institute of Mental Health (NIMH) Grant Nos. U01MH092221 (to MHT) and U01MH092250 (to PJM, RVP, MMW), the EMBARC National Coordinating Center at University of Texas Southwestern Medical Center; and the Data Center at Columbia University and Stony Brook University.

The content is solely the responsibility of the authors and does not necessarily represent the official views of the $\mathrm{NIH}$. The funders had no role 
Neuroticism and Brain Function in Depression

in the design and conduct of the study; collection, management, analysis, and interpretation of the data; preparation, review, or approval of the manuscript; or decision to submit the manuscript for publication.

Valeant Pharmaceuticals donated the Wellbutrin XL used in the EMBARC study.

$\mathrm{AE}$ has consulted for Otsuka Pharmaceuticals and received grant funding from Brain Resource, Inc. TD has received support from $\mathrm{NIH}$, $\mathrm{NIMH}$, National Alliance for Research on Schizophrenia and Depression (NARSAD), Tourette Syndrome Association, International OCD Foundation, Tufts University, Depression and Bipolar Disorder Alternative Treatment Foundation, and Otsuka Pharmaceuticals; has received honoraria, consultation fees, or royalties from Massachusetts General Hospital (MGH) Psychiatry Academy, BrainCells Inc., Clintara, LLC, Systems Research and Applications Corporation, Boston University, Catalan Agency for Health Technology Assessment and Research, National Association of Social Workers Massachusetts, Massachusetts Medical Society, Tufts University, NIDA, NIMH, Oxford University Press, Guilford Press, and Rutledge; and has participated in research funded by Defense Advanced Research Projects Agency, $\mathrm{NIH}, \mathrm{NIMH}$, National Institute on Aging, Agency for Healthcare Research and Quality, Patient-Centered Outcomes Research Institute, Janssen Pharmaceuticals, Forest Research Institute, Shire Development Inc., Medtronic, Cyberonics, Northstar, and Takeda. MT has consulted for Otsuka Pharmaceuticals; has received travel funds from Janssen Research and Development; and has received research funding from NIMH and Brain and Behavior Research Foundation. BK has received research grant support from Targacept, Inc., Pfizer Inc., Johnson \& Johnson, Evotec, Rexahn, Naurex, Forest Pharmaceuticals, Inc., and NIMH. MGM has served as a consultant for Janssen Pharmaceuticals. MAO receives royalties from Research Foundation for Mental Hygiene for the commercial use of the Columbia-Suicide Severity Rating Scale; her family owns stock in Bristol-Myers Squibb. PJM has received research grant support from Forest Research Laboratories, Sunovion Pharmaceuticals, and Naurex. MF has received research support from Abbott Laboratories, Alkermes, Inc., American Cyanamid, Aspect Medical Systems, AstraZeneca, Avanir Pharmaceuticals, BioResearch, BrainCells Inc., Bristol-Myers Squibb, CeNeRx BioPharma, Cephalon, Cerecor, Clintara, LLC, Covance, Covidien, Eli Lilly and Company, EnVivo Pharmaceuticals, Inc., Euthymics Bioscience, Inc., Forest Pharmaceuticals, Inc., Ganeden Biotech, Inc., GlaxoSmithKline, Harvard Clinical Research Institute, Hoffman-LaRoche, Icon Clinical Research, i3 Innovus/Ingenix, Janssen R\&D, LLC, Jed Foundation, Johnson \& Johnson Pharmaceutical Research \& Development, Lichtwer Pharma GmbH, Lorex Pharmaceuticals, Lundbeck Inc., MedAvante, Methylation Sciences Inc., NARSAD, National Center for Complementary and Alternative Medicine, Neuralstem, Inc., NIDA, NIMH, Novartis AG, Organon Pharmaceuticals, PamLab, LLC, Pfizer Inc., PharmaciaUpjohn, Pharmaceutical Research Associates, Inc., Pharmavite LLC, PharmoRx Therapeutics, Photothera, Reckitt Benckiser, Roche Pharmaceuticals, RCT Logic, LLC (formerly Clinical Trials Solutions, LLC), SanofiAventis US LLC, Shire, Solvay Pharmaceuticals, Inc., Stanley Medical Research Institute, Synthelabo, Tal Medical, and Wyeth-Ayerst Laboratories; has served on the advisory board or consulted for Abbott Laboratories, Acadia, Affectis Pharmaceuticals AG, Alkermes, Inc., Amarin Pharma Inc., Aspect Medical Systems, AstraZeneca, Auspex Pharmaceuticals, Avanir Pharmaceuticals, AXSOME Therapeutics, Bayer AG, Best Practice Project Management, Inc., Biogen, BioMarin Pharmaceuticals, Inc., Biovail Corporation, BrainCells Inc., Bristol-Myers Squibb, CeNeRx BioPharma, CephaIon, Inc., Cerecor, CNS Response, Inc., Compellis Pharmaceuticals, Cypress Pharmaceutical, Inc., DiagnoSearch Life Sciences (P) Ltd., Dinippon Sumitomo Pharma Co. Inc., Dov Pharmaceuticals, Inc., Edgemont Pharmaceuticals, Inc., Eisai Inc., Eli Lilly and Company, EnVivo Pharmaceuticals, Inc., ePharmaSolutions, EPIX Pharmaceuticals, Inc., Euthymics Bioscience, Inc., Fabre-Kramer Pharmaceuticals, Inc., Forest Pharmaceuticals, Inc., Forum Pharmaceuticals, GenOmind, LLC, GlaxoSmithKline, Grunenthal $\mathrm{GmbH}$, i3 Innovus/Ingenis, Intracellular, Janssen Pharmaceutica, Jazz Pharmaceuticals, Inc., Johnson \& Johnson Pharmaceutical Research \& Development, LLC, Knoll Pharmaceuticals Corp., Labopharm Inc., Lorex Pharmaceuticals, Lundbeck Inc., MedAvante, Inc., Merck \& Co., Inc., MSI Methylation Sciences, Inc., Naurex, Inc., Nestle Health Sciences, Neuralstem, Inc., Neuronetics, Inc., NextWave Pharmaceuticals, Novartis AG, Nutrition 21, Orexigen Therapeutics, Inc., Organon Pharmaceuticals,
Osmotica, Otsuka Pharmaceuticals, Pamlab, LLC, Pfizer Inc., Pharmaceutical Product Development, LLC, PharmaStar, Pharmavite LLC, PharmoRx Therapeutics, Precision Human Biolaboratory, Prexa Pharmaceuticals, Inc., Puretech Ventures, PsychoGenics, Psylin Neurosciences, Inc., RCT Logic, LLC (formerly Clinical Trials Solutions, LLC), Rexahn Pharmaceuticals, Inc., Ridge Diagnostics, Inc., Roche, Sanofi-Aventis US LLC, Sepracor Inc., Servier Laboratories, Schering-Plough Corporation, Solvay Pharmaceuticals, Inc., Somaxon Pharmaceuticals, Inc., Somerset Pharmaceuticals, Inc., Sunovion Pharmaceuticals, Supernus Pharmaceuticals, Inc., Synthelabo, Taisho Pharmaceutical, Takeda Pharmaceutical Company Limited, Tal Medical, Inc., Tetragenex Pharmaceuticals, Inc., TransForm Pharmaceuticals, Inc., Transcept Pharmaceuticals, Inc., Vanda Pharmaceuticals, Inc., and VistaGen Therapeutics; has received speaking or publishing fees from Adamed, Co., Advanced Meeting Partners, American Psychiatric Association, American Society of Clinical Psychopharmacology, AstraZeneca, Belvoir Media Group, Boehringer Ingelheim $\mathrm{GmbH}$, Bristol-Myers Squibb, Cephalon, Inc., CME Institute/Physicians Postgraduate Press, Inc., Eli Lilly and Company, Forest Pharmaceuticals, Inc., GlaxoSmithKline, Imedex LLC, Lippincott Williams \& Wilkins, MGH Psychiatry Academy/Primedia, MGH Psychiatry Academy/Reed Elsevier, Novartis AG, Organon Pharmaceuticals, Pfizer Inc., PharmaStar, United BioSource Corp., Wolters Kluwer, World Scientific Publishing Co. Pte. Ltd., and Wyeth-Ayerst Laboratories; has equity holdings in Compellis and PsyBrain, Inc.; holds patents for Sequential Parallel Comparison Design, licensed by MGH to Pharmaceutical Product Development, LLC, and patent application for a combination of Ketamine plus Scopolamine in Major Depressive Disorder, licensed by MGH to Biohaven; and holds copyrights for the MGH Cognitive \& Physical Functioning Questionnaire, Sexual Functioning Inventory, Antidepressant Treatment Response Questionnaire, Discontinuation-Emergent Signs \& Symptoms, Symptoms of Depression Questionnaire, and SAFER. MW received funding from NIMH, NIDA, NARSAD, Sackler Foundation, and Templeton Foundation and receives royalties from Oxford University Press, Perseus Press, American Psychiatric Association Press, and MultiHealth Systems. MHT is or has been an advisor/consultant and received fees from Abbott Laboratories, Inc., Abdi Ibrahim, Akzo (Organon Pharmaceuticals Inc.), Alkermes, AstraZeneca, Axon Advisors, Bristol-Myers Squibb, Cephalon, Inc., Cerecor, CME Institute of Physicians, Concert Pharmaceuticals, Inc., Eli Lilly and Company, Evotec, Fabre Kramer Pharmaceuticals, Inc., Forest Pharmaceuticals, Inc., GlaxoSmithKline, Janssen Global Services, LLC, Janssen Pharmaceutica Products, LP, Johnson \& Johnson Pharmaceutical Research \& Development, LLC, Libby, Lundbeck, Meade Johnson, MedAvante, Medtronic, Merck, Mitsubishi Tanabe Pharma Development America, Inc., Naurex, Neuronetics, Otsuka Pharmaceuticals, Pamlab, Parke-Davis Pharmaceuticals, Inc., Pfizer Inc., PgxHealth, Phoenix Marketing Solutions, Rexahn Pharmaceuticals, Ridge Diagnostics, Roche Products Ltd., Sepracor, Shire Development Inc., Sierra, SK Life and Science, Sunovion, Takeda, Tal Medical/Puretech Venture, Targacept, Transcept, VantagePoint, Vivus, and Wyeth-Ayerst Laboratories and has received grants and/or research support from Agency for Healthcare Research and Quality, Cyberonics, Inc., NARSAD, NIMH, and NIDA. MLP serves as a consultant to Roche Pharmaceuticals.

All other authors report no biomedical financial interests or potential conflicts of interest.

ClinicalTrials.gov: Establishing Moderators and Biosignatures of Antidepressant Response for Clinical Care for Depression (EMBARC); http:// clinicaltrials.gov/show/NCT01407094; Identifier: NCT01407094.

\section{ARTICLE INFORMATION}

From the Department of Psychiatry (JCF, HWC, TG, RS, MLP), University of Pittsburgh School of Medicine, Pittsburgh, Pennsylvania; Department of Psychiatry (AE), Stanford University School of Medicine, Stanford, California; Department of Psychiatry and Human Behavior (JRA), Alpert Medical School of Brown University, Providence, Rhode Island; Department of Psychiatry (TD, MF), Massachusetts General Hospital, Boston, Massachusetts; Department of Psychiatry (SW, CC, MT, TC, BK, MHT), University of Texas Southwestern Medical Center, Dallas, Texas; Functional MRI Laboratory (SP), University of Michigan; Department of Psychiatry (MGM), University of Michigan Medical School, Ann Arbor, Michigan; Department 
of Psychiatry (PA, MAO, PJM, MW), Columbia University College of Physicians and Surgeons and the New York State Psychiatric Institute, New York; and Departments of Psychiatry and Behavioral Science and Radiology (RP), Stony Brook University, Stony Brook, New York.

Address correspondence to Jay Fournier, Ph.D., Department of Psychiatry, University of Pittsburgh School of Medicine, 3811 O'Hara Street, Pittsburgh, PA 15213; E-mail: fournierjc@upmc.edu.

Received Aug 12, 2016; revised Nov 11, 2016; accepted Nov 22, 2016.

Supplementary material cited in this article is available online at http:// dx.doi.org/10.1016/j.bpsc.2016.11.008.

\section{REFERENCES}

1. Costa PT, McCrae RR (1992): Revised NEO Personality Inventory (NEO-PI-R) and NEO Five-Factor Inventory (NEO-FFI) Professional Manual. Odessa, FL: Psychological Assessment Resources.

2. Hengartner MP (2015): The detrimental impact of maladaptive personality on public mental health: A challenge for psychiatric practice. Front Psychiatry 6:87

3. Lahey BB (2009): Public health significance of neuroticism. Am Psychol 64:241-256.

4. Fournier J, Tang TZ (in press): Personality in depression. In: DeRubeis RJ, Strunk DR, editors. The Oxford Handbook of Mood Disorders. New York: Oxford University Press. http://www.oxfordhandbooks.com/view/10.1093/ oxfordhb/9780199973965.001.0001/oxfordhb-9780199973965-e-14.

5. Clark LA (2005): Temperament as a unifying basis for personality and psychopathology. J Abnorm Psychol 114:505-521.

6. Kotov R, Gamez W, Schmidt F, Watson D (2010): Linking "big" personality traits to anxiety, depressive, and substance use disorders: A meta-analysis. Psychol Bull 136:768-821.

7. Krueger RF, Tackett JL (2003): Personality and psychopathology: Working toward the bigger picture. J Pers Disord 17:109-128.

8. Watson D, Clark LA (1995): Depression and the melancholic temperament. Eur J Pers 9:351-366.

9. Bagby RM, Psych C, Quilty LC, Ryder AC (2008): Personality and depression. Can J Psychiatry 53:14-25.

10. Simon GE, Perlis RH (2010): Personalized medicine for depression: Can we match patients with treatments? Am J Psychiatry 167: 1445-1455.

11. Fournier JC, DeRubeis RJ, Shelton RC, Gallop R, Amsterdam JD, Hollon SD (2008): Antidepressant medications v. cognitive therapy in people with depression with or without personality disorder. $\mathrm{Br}$ J Psychiatry 192:124-129.

12. Bagby RM, Quilty LC, Segal ZV, McBride CC, Kennedy SH, Costa PT Jr (2008): Personality and differential treatment response in major depression: A randomized controlled trial comparing cognitivebehavioural therapy and pharmacotherapy. Can J Psychiatry 53: 361-370.

13. Hollon SD, Jarrett RB, Nierenberg AA, Thase ME, Trivedi M, Rush AJ (2005): Psychotherapy and medication in the treatment of adult and geriatric depression: Which monotherapy or combined treatment? J Clin Psychiatry 66:455-468.

14. Quilty LC, De Fruyt F, Rolland JP, Kennedy SH, Rouillon PF, Bagby RM (2008): Dimensional personality traits and treatment outcome in patients with major depressive disorder. J Affect Disord 108:241-250.

15. Tang TZ, DeRubeis RJ, Hollon SD, Amsterdam J, Shelton R, Schalet B (2009): Personality change during depression treatment: A placebocontrolled trial. Arch Gen Psychiatry 66:1322-1330.

16. Maddux RE, Riso LP, Klein DN, Markowitz JC, Rothbaum BO, Arnow BA, et al. (2009): Select comorbid personality disorders and the treatment of chronic depression with nefazodone, targeted psychotherapy, or their combination. J Affect Disord 117:174-179.

17. Levenson JC, Wallace ML, Fournier JC, Rucci P, Frank E (2012): The role of personality pathology in depression treatment outcome with psychotherapy and pharmacotherapy. J Consult Clin Psychol 80: 719-729.

18. Ormel J, Bastiaansen A, Riese H, Bos EH, Servaas M, Ellenbogen M, et al. (2013): The biological and psychological basis of neuroticism:
Current status and future directions. Neurosci Biobehav Rev 37: 59-72.

19. Eysenck HJ (1967): The Biological Basis of Personality. Springfield, IL Thomas.

20. Phillips ML, Ladouceur CD, Drevets WC (2008): A neural model of voluntary and automatic emotion regulation: Implications for understanding the pathophysiology and neurodevelopment of bipolar disorder. Mol Psychiatry 13:833-857.

21. Gyurak A, Gross JJ, Etkin A (2011): Explicit and implicit emotion regulation: A dual-process framework. Cogn Emot 25:400-412.

22. Menon V, Uddin LQ (2010): Saliency, switching, attention and control: A network model of insula function. Brain Struct Funct 214: 655-667.

23. Uddin LQ (2014): Salience processing and insular cortical function and dysfunction. Nat Rev Neurosci 16:55-61.

24. Haas BW, Omura K, Constable RT, Canli T (2007): Emotional conflict and neuroticism: Personality-dependent activation in the amygdala and subgenual anterior cingulate. Behav Neurosci 121:249-256.

25. Wallace JF, Newman JP (1997): Neuroticism and the attentional mediation of dysregulatory psychopathology. Cogn Ther Res 21: 135-156.

26. Wallace JF, Newman JP (1998): Neuroticism and the facilitation of the automatic orienting of attention. Pers Individ Dif 24:253-266.

27. Bredemeier K, Berenbaum H, Most SB, Simons DJ (2011): Links between neuroticism, emotional distress, and disengaging attention: Evidence from a single-target RSVP task. Cogn Emot 25:1510-1519.

28. Pauli WM, Röder B (2008): Emotional salience changes the focus of spatial attention. Brain Res 1214:94-104.

29. Wyble B, Sharma D, Bowman H (2008): Strategic regulation of cognitive control by emotional salience: A neural network model. Cogn Emot 22:1019-1051.

30. Wu CC, Samanez-Larkin GR, Katovich K, Knutson B (2014): Affective traits link to reliable neural markers of incentive anticipation. Neuroimage 84:279-289

31. Stein MB, Simmons AN, Feinstein JS, Paulus MP (2007): Increased amygdala and insula activation during emotion processing in anxietyprone subjects. Am J Psychiatry 164:318-327.

32. Coen SJ, Kano M, Farmer AD, Kumari V, Giampietro V, Brammer M, et al. (2011): Neuroticism influences brain activity during the experience of visceral pain. Gastroenterology 141:909-917.

33. Feinstein JS, Stein MB, Paulus MP (2006): Anterior insula reactivity during certain decisions is associated with neuroticism. Soc Cogn Affect Neurosci 1:136-142

34. Paulus MP, Rogalsky C, Simmons A, Feinstein JS, Stein MB (2003): Increased activation in the right insula during risk-taking decision making is related to harm avoidance and neuroticism. Neuroimage 19 1439-1448

35. Pizzagalli DA (2010): Frontocingulate dysfunction in depression: Toward biomarkers of treatment response. Neuropsychopharmacology 36:183-206.

36. Siegle GJ, Carter CS, Thase ME (2006): Use of $\mathrm{fMRI}$ to predict recovery from unipolar depression with cognitive behavior therapy. Am J Psychiatry 163:735-738

37. Siegle GJ, Thompson WK, Collier A, Berman SR, Feldmiller J, Thase ME, et al. (2012): Toward clinically useful neuroimaging in depression treatment: Prognostic utility of subgenual cingulate activity for determining depression outcome in cognitive therapy across studies, scanners, and patient characteristics. Arch Gen Psychiatry 69: 913-924.

38. McGrath CL, Kelley ME, Holtzheimer PE, Dunlop BW, Craighead WE, Franco AR, et al. (2013): Toward a neuroimaging treatment selection biomarker for major depressive disorder. JAMA Psychiatry 70 : 821-829.

39. Cromheeke S, Mueller SC (2013): Probing emotional influences on cognitive control: An ALE meta-analysis of cognition emotion interactions. Brain Struct Funct 219:995-1008.

40. Greenberg T, Chase HW, Almeida JR, Stiffler R, Zevallos CR, Aslam HA, et al. (2015): Moderation of the relationship between reward expectancy and prediction error-related ventral striatal reactivity by 
anhedonia in unmedicated major depressive disorder: Findings from the EMBARC study. Am J Psychiatry 172:881-891.

41. Trivedi MH, McGrath PJ, Fava M, Parsey RV, Kurian BT, Phillips ML, et al. (2016): Establishing moderators and biosignatures of antidepressant response in clinical care (EMBARC): Rationale and design. J Psychiatr Res 78:11-23.

42. First M, Spitzer R, Gibbon M, Williams J (2002): Structured Clinical Interview for DSM-IV-TR Axis I Disorders, Research Version, Patient Edition (SCID-I/P). New York: Biometrics Research, New York State Psychiatric Institute.

43. McCrae RR, Costa PT (2010): NEO Inventories: NEO Personality Inventory-3 (NEO-PI-3). Lutz, FL: Psychological Assessment Resources.

44. Uliaszek AA, Hauner KKY, Zinbarg RE, Craske MG, Mineka S, Griffith JW, et al. (2009): An examination of content overlap and disorderspecific predictions in the associations of neuroticism with anxiety and depression. J Res Pers 43:785-794.

45. Hamilton MA (1960): A rating scale for depression. J Neurol Neurosurg Psychiatry 23:56-62.

46. Watson D, Clark LA, Weber K, Assenheimer JS, Strauss ME, McCormick RA (1995): Testing a tripartite model: II. Exploring the symptom structure of anxiety and depression in student, adult, and patient samples. J Abnorm Psychol 104:15-25.

47. Watson D, Weber K, Assenheimer JS, Clark LA, Strauss ME, McCormick RA (1995): Testing a tripartite model: I. Evaluating the convergent and discriminant validity of anxiety and depression symptom scales. J Abnorm Psychol 104:3-14.

48. Etkin A, Egner T, Peraza DM, Kandel ER, Hirsch J (2006): Resolving emotional conflict: A role for the rostral anterior cingulate cortex in modulating activity in the amygdala. Neuron 51:871-882.

49. Carter CS, Lesh TA, Barch DM (2016): Thresholds, power, and sample sizes in clinical neruoimaging. Biol Psychiatry Cogn Neurosci Neuroimaging 1:99-100.

50. McLaren DG, Ries ML, Xu G, Johnson SC (2012): A generalized form of context-dependent psychophysiological interactions (gPPI): A comparison to standard approaches. Neuroimage 61:1277-1286.

51. Deen B, Pitskel NB, Pelphrey KA (2011): Three systems of insular functional connectivity identified with cluster analysis. Cereb Cortex 21:1498-1506.

52. Cameron AC, Trivedi PK (2009): Microeconometrics Using Stata. College Station, TX: Stata Press.

53. Bagby RM, Young LT, Schuller DR, Bindseil KD, Cooke RG, Dickens SE, et al. (1996): Bipolar disorder, unipolar depression and the FiveFactor Model of Personality. J Affect Disord 41:25-32.

54. Bianchi R, Laurent E (2016): Depressive symptomatology should be systematically controlled for in neuroticism research. Neuroimage 125:1099-1100.

55. Riese H, Ormel J, Aleman A, Servaas MN, Jeronimus BF (2016): Don't throw the baby out with the bathwater: Depressive traits are part and parcel of neuroticism. Neuroimage 125:1103.

56. Yeo BTT, Krienen FM, Sepulcre J, Sabuncu MR, Lashkari D, Hollinshead M, et al. (2011): The organization of the human cerebral cortex estimated by intrinsic functional connectivity. J Neurophysiol 106: 1125-1165.
57. Horwood LJ, Fergusson DM (1986): Neuroticism, depression and life events: A structural equation model. Soc Psychiatry 21:63-71.

58. Kornør H, Nordvik H (2007): Five-factor model personality traits in opioid dependence. BMC Psychiatry 7:37.

59. Park M, Hennig-Fast K, Bao Y, Carl P, Pöppel E, Welker L, et al. (2013): Personality traits modulate neural responses to emotions expressed in music. Brain Res 1523:68-76.

60. Conway CR, Chibnall JT, Gangwani S, Mintun MA, Price JL, Hershey T, et al. (2012): Pretreatment cerebral metabolic activity correlates with antidepressant efficacy of vagus nerve stimulation in treatmentresistant major depression: A potential marker for response? J Affect Disord 139:283-290.

61. Sridharan D, Levitin DJ, Menon V (2008): A critical role for the right fronto-insular cortex in switching between central-executive and default-mode networks. Proc Natl Acad Sci U S A 105: 12569-12574.

62. Jilka SR, Scott G, Ham T, Pickering A, Bonnelle V, Braga RM, et al. (2014): Damage to the salience network and interactions with the default mode network. J Neurosci 34:10798-10807.

63. Raichle ME, MacLeod AM, Snyder AZ, Powers WJ, Gusnard DA, Shulman GL (2001): A default mode of brain function. Proc Natl Acad Sci U S A 98:676-682.

64. Raichle ME, Snyder AZ (2007): A default mode of brain function: A brief history of an evolving idea. Neuroimage 37:1083-1090.

65. Sheline YI, Barch DM, Price JL, Rundle MM, Vaishnavi SN, Snyder AZ, et al. (2009): The default mode network and self-referential processes in depression. Proc Natl Acad Sci U S A 106:1942-1947.

66. Hamilton JP, Furman DJ, Chang C, Thomason ME, Dennis E, Gotlib IH (2011): Default-mode and task-positive network activity in major depressive disorder: Implications for adaptive and maladaptive rumination. Biol Psychiatry 70:327-333.

67. Webb CA, Dillon DG, Pechtel P, Goer FK, Murray L, Huys QJ, et al. (2015): Neural correlates of three promising endophenotypes of depression: Evidence from the EMBARC study. Neuropsychopharmacology 41:454-463.

68. Wagner G, Sinsel E, Sobanski T, Köhler S, Marinou V, Mentzel H-J, et al. (2006): Cortical inefficiency in patients with unipolar depression: An event-related FMRI study with the Stroop task. Biol Psychiatry 59: 958-965.

69. George MS, Ketter TA, Parekh PI, Rosinsky N, Ring HA, Pazzaglia PJ, et al. (1997): Blunted left cingulate activation in mood disorder subjects during a response interference task (the Stroop). J Neuropsychiatry Clin Neurosci 9:55-63.

70. Mitterschiffthaler MT, Williams SCR, Walsh ND, Cleare AJ, Donaldson C, Scott J, et al. (2008): Neural basis of the emotional Stroop interference effect in major depression. Psychol Med 38: 247-256.

71. Chechko N, Augustin M, Zvyagintsev M, Schneider F, Habel U, Kellermann T (2013): Brain circuitries involved in emotional interference task in major depression disorder. J Affect Disord 149:136-145.

72. Insel T, Cuthbert B, Garvey M, Heinssen R, Pine DS, Quinn K, et al. (2010): Research domain criteria (RDoC): Toward a new classification framework for research on mental disorders. Am J Psychiatry 167: $748-751$. 